\title{
SELECTION OF A FILLER FOR TABLETS MANUFACTURED WITH DIRECT COMPRESSION METHOD CONTAINING DRY GINGER EXTRACT
}

\author{
Olena Ruban \\ Department of Industrial Technology of Drugs \\ National University of Pharmacy \\ 53 Pushkinska str., Kharkiv, Ukraine, 61002 \\ ruban_elen@ukr.net \\ Malek Alkhalaf \\ Department of Industrial Technology of Drugs \\ National University of Pharmacy \\ 53 Pushkinska str., Kharkiv, Ukraine, 61002 \\ malekwalkhalaf@gmail.com \\ Nataliia Gerbina \\ Department of Industrial Technology of Drugs \\ National University of Pharmacy \\ 53 Pushkinska str., Kharkiv, Ukraine, 61002 \\ n.a.gerbina@gmail.com
}

\begin{abstract}
The preliminary studies of physico-chemical and pharmaco-technological properties of the dry extract of ginger have determined the need for introduction of different groups of excipients for developing a solid dosage form for the treatment of type II diabetes mellitus.

Aim. To choose the rational filler in the composition of tablets with ginger obtained by direct compression.

Materials and methods. The study object was the dry extract of ginger (DEG) (producer "Megaprom", Dnepr, Ukraine) and modern excipients for the production of tablets by direct compression: GalenIQ 721 (BENEO-Palatinit Gmb), Flowlac 100 (Meggle Co.), Tablettose 80 (Meggle Co.), Farmaxx (Merck), Microcelac 100 (Meggle Co.), Vivapur 112 and 102 (JRS Pharm), Prosolv HD 90, Prosolv SMCC 50 (JRS Pharm) manufactured in Germany. Pharmaco-technological and physico-chemical properties of the samples were studied according to conventional methods of the State Pharmacopoeia of Ukraine.

Results and discussion. According to the results of the crystallographic analysis, the ability to the moisture absorption, resistance to crushing, disintegration time, fluidity indicators, angle of repose and bulk volume the effect of modern excipients on physicochemical and pharmaco-technological properties of the dry extract of ginger has been studied.

Conclusions. According to the results of microscopic analysis, it has been found, that the rational fillers are GalenIQ 721, Prosolv HD 90, Prosolv SMCC 50, Vivapur 102 and Vivapur 112, as they provide a uniform system and the necessary resistance to destruction. The study of the kinetics of the moisture absorption has shown that addition of the fillers significantly reduces the increase in moisture compared to the dry extract. The mixture with GalenIQ 721 has the lowest parameters of moisture absorption at a relative air humidity of $45 \%, 75 \%$ and $100 \%$. In accordance with the results of the pharmaco-technological studies, it has been found that addition of GalenIQ 721 leads to improved flowability, disintegration, settling qualities; it indicates the feasibility of its inclusion into the composition of the solid dosage form.

Keywords: type II diabetes mellitus, phytotherapy, dry extract, ginger, Galen IQ 721, excipients, fillers, tablets, direct compression.
\end{abstract}

\section{Introduction}

Diabetes mellitus (DM) is one of the major medical and social problems of our time related to the priority areas of national health systems in almost all countries of the world $[1,2]$. Its prevalence is high in both developing and developed countries. By the medical and social significance DM occupies the "honorable" third place due to the fact that every year labor losses and economic damage increase as a result of morbidity, disability and mortality 
of the population, the costs of the state and society aimed at the treatment of the disease and its complications [3, 4].

Phytotherapy is one of the most common and effective auxiliary methods in the treatment of type I and II diabetes mellitus [5, 6]. If the disease can be detected in the early stages, phytotherapy in combination with a diet and dosed physical activity can stabilize the condition of many patients without drug treatment [7].

Medicinal plants have a number of advantages over synthetic drugs: they are low-toxic, have a mild effect, can be used for a long time without significant side effects, especially allergic reactions, combined well with drugs, enhancing their therapeutic effect $[8,9]$.

One of the plants exhibiting a multifaceted range of therapeutic properties on the human body is ginger (Zingiber officinale) $[10,11]$. According to the preliminary pharmacological studies conducted the presence of hypoglycemic action of the dry ginger extract was proven [12, 13], which confirmed the feasibility of developing a solid dosage form based on it.

When studying physicochemical and pharmaco-technological properties of the dry extract of ginger it was found that it had a heterogeneous structure with transparent particles of a light brown color with linear particle sizes from 0.1 to $1 \mu \mathrm{m}$, the average value of the form factor -0.7 . The substance is hygroscopic, has poor flowability and compressibility. It confirmed the need for introduction of different groups of excipients [14].

During development of the composition and technology of tablets with the dry extract of ginger it is rational to use the method of direct compression, which eliminates the impact of moisture on the active substances in the production process, reduces the risk of microbial contamination, decreases the amount of excipients, as well as saves production space, thereby reducing equipment and energy costs $[15,16]$.

\section{Aim of research}

The aim of the work is to choose the rational filler in the composition of tablets on the basis of ginger obtained by direct compression.

\section{Materials and methods}

The study was performed on the basis of State scientific-research laboratory for medicinal substances quality control of the National University of Pharmacy in 2018.

The study object was the dry extract of ginger (DEG) (producer "Megaprom", Dnepr, Ukraine) and modern excipients for the production of tablets by direct compression: GalenIQ 721isomalt (polyol) (BENEO-Palatinit Gmb), Flowlac 100 - a mixture of $85 \% \alpha$-lactose monohydrate and $15 \%$ amorphous lactose, (Meggle Co.), Tablettose 80 - agglomerated lactose monohydrate (Meggle Co.), Farmaxx - a mixture of $70 \%$ calcium carbonate and $30 \%$ sorbitol, (Merck), Microcelac 100 - a mixture of $75 \% \alpha$-lactose monohydrate and $25 \%$ microcrystalline cellulose, (Meggle Co.), Vivapur 112 and 102 - microcrystalline cellulose (JRS Pharm), Prosolv HD 90, Prosolv SMCC 50 - a mixture of $98 \%$ microcrystalline cellulose and $2 \%$ colloidal silicon dioxide (JRS Pharm) manufactured in Germany [17].

The pharmaco-technological properties were studied according to conventional methods: microscopic analysis, flowability, bulk density, tapped density, Carr index, Hausner index, resistance, disintegration and moisture absorption [18, 19]. The flowability was determined according to the method of the State Pharmacopoeia of Ukraine (SPhU), II ed., using a funnel with a $15 \mathrm{~mm}$ hole diameter [20].

The bulk volume and bulk density were studied on a 545P-AK-3-RT-TD device for vibration compaction of powders (PHARMA TEST, Germany).

Carr Index and Hausner Index were calculated by formulas 1 and 2, respectively:

Carr Index

$$
\mathrm{C}=\frac{\mathrm{V}_{0}-\mathrm{V}_{1250}}{\mathrm{~V}_{0}} * 100 \% \text {. }
$$


Hausner Index

$$
H R=\frac{V_{0}}{V_{125 o}},
$$

where $\mathrm{V}_{0}$ - is the bulk volume; $\mathrm{V}_{1250}$ - is the settled volume.

Resistance and disintegration of the tablets were studied on a PJ-3 tablet four-use tester (China).

The crystallographic studies were performed a "KONUS - Academy" laboratory microscope with 40 times magnification of the eyepiece and a built-in camera.

The moisture absorption was studied at a relative humidity of $45 \%, 75 \%$ and $100 \%$. Within 6 hours of the experiment, the change in the mass of the powder in the laboratory desiccator was recorded. The relative air humidity of $75 \%$ was created with the help of a saturated solution of sodium chloride, and potassium carbonate formed $45 \%$ of humidity.

\section{Research results}

Primarily, to determine the qualitative characteristics of tableting masses microscopic studies of DEG mixture with different fillers in the ratio of 1:1 were conducted. The results are presented in Fig. 1-7.

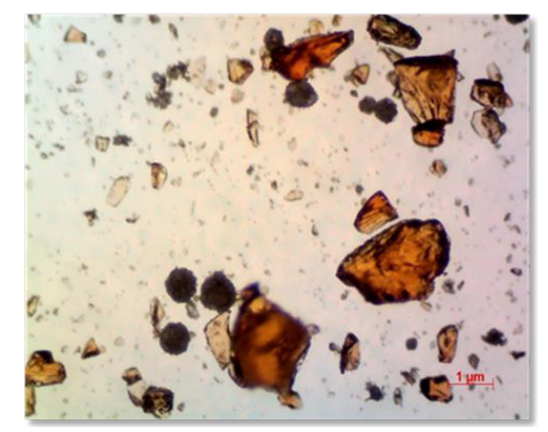

Fig. 1. The mixture of DEG and Flowlac 100

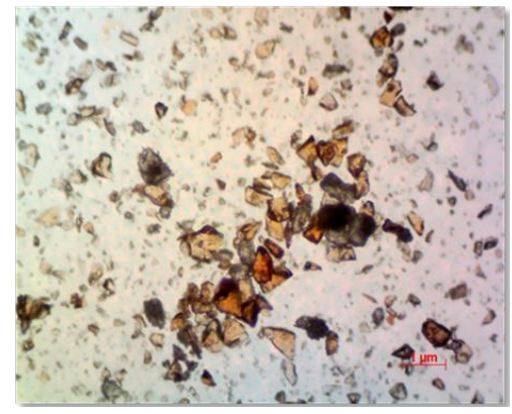

Fig. 2. The mixture of DEG and Tablettose 80

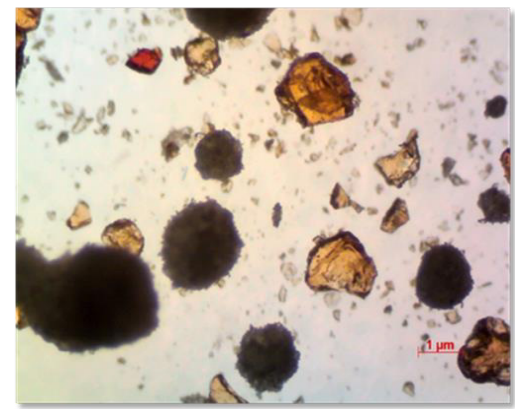

Fig. 3. The mixture of DEG and Microcelac 100 


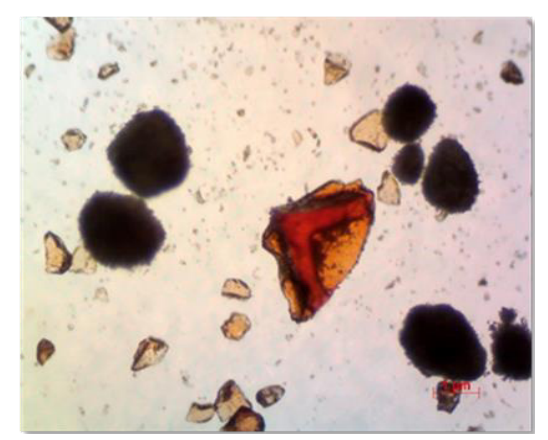

Fig. 4. The mixture of DEG and Farmaxx

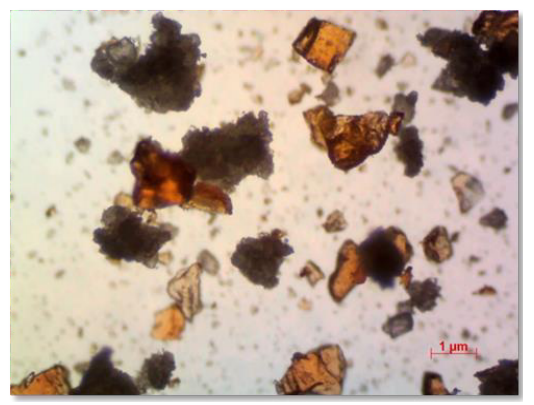

Fig. 5. The mixture of DEG and GalenIQ 721

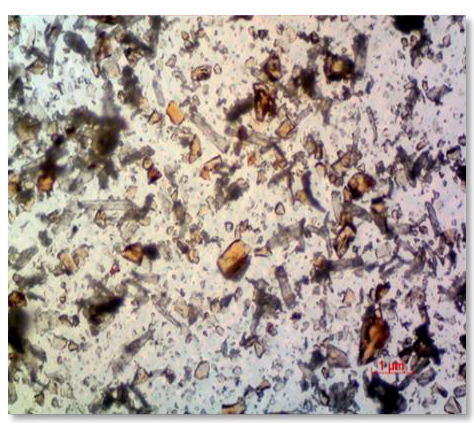

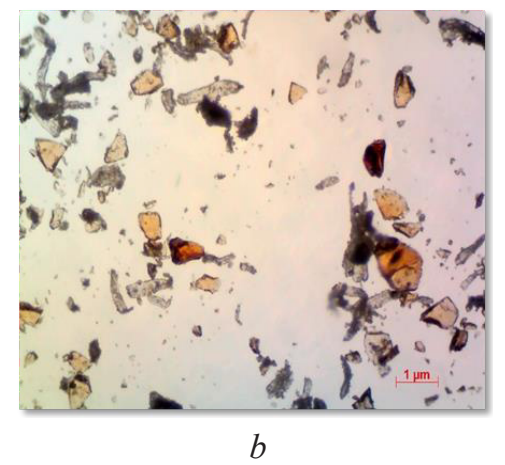

Fig. 6. The mixture of DEG with: $a$ - Vivapur 112; $b$ - Vivapur 102
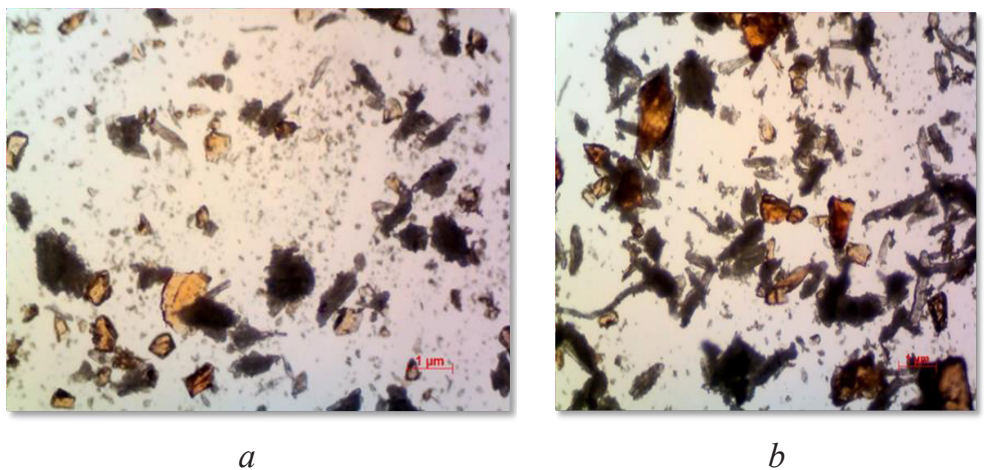

Fig. 7. The mixture of SEG with: $a$ - Prosolv HD 90; $b$ - Prosolv SMCC 50

To conduct further research, the model tablets with the fillers were manufactured, after that, the resistance of tablets to crushing on a PJ-3 Tablet Four-use Tester was studied. The results of the studies are shown in Fig. 8. 


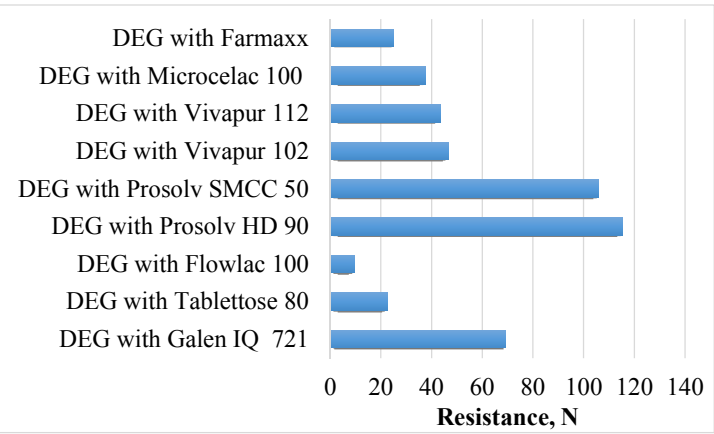

Fig. 8. Indicators of resistance to crushing of model tablets with different fillers

Thus, taking into account the results of the microscopic analysis and indicators of tablet resistance to crushing the samples with such fillers as GalenIQ 721, Prosolv HD 90, Prosolv SMCC 50, Vivapur 102 and Vivapur 112 were selected for further research.

It is known that all plant components are hygroscopic substances. Therefore, we studied how fillers affected the moisture absorption of DEG at a relative humidity of $45 \%, 75 \%$ and $100 \%$.

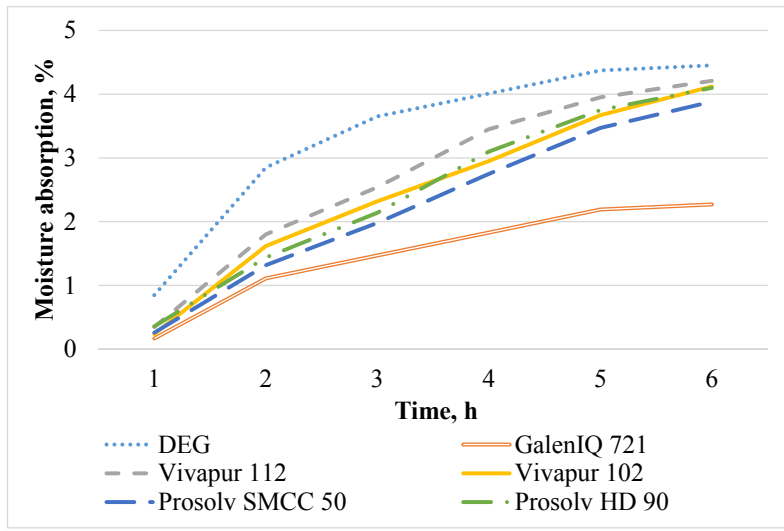

Fig. 9. Kinetics of the moisture absorption of DEG and DEG samples with different fillers at a relative humidity of $45 \%$

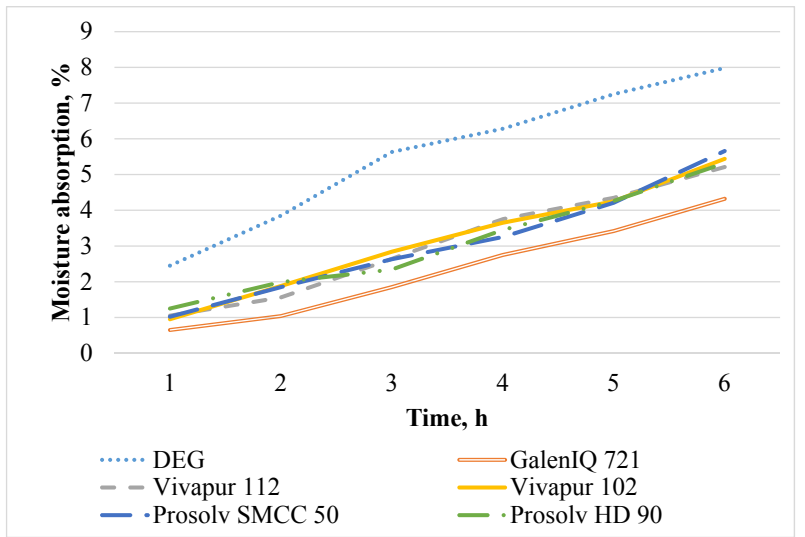

Fig. 10. Kinetics of the moisture absorption of DEG and DEG samples with different fillers at a relative humidity of $75 \%$

For the final selection of the filler, the pharmaco-technological properties of the samples with DEG were studied. The results are given in Table $\mathbf{1 .}$ 


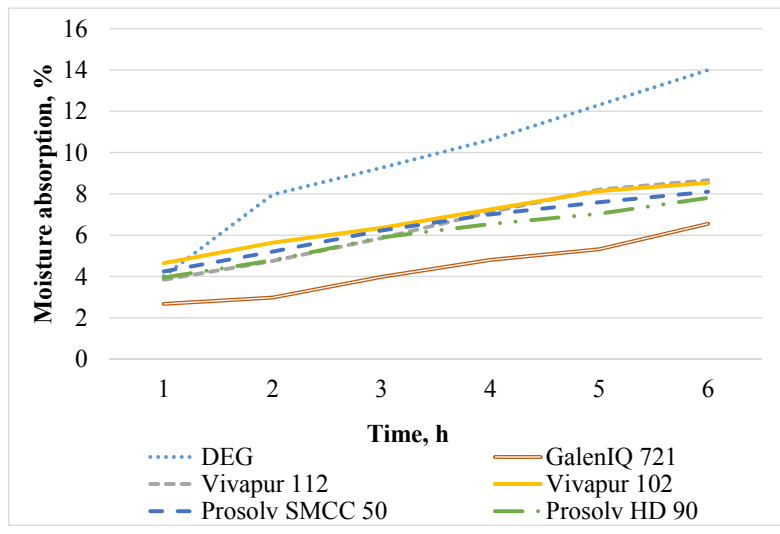

Fig. 11. Kinetics of the moisture absorption of DEG and DEG samples with different fillers at a relative humidity of $100 \%$

Table 1

The pharmaco-technological properties of the samples with DEG with different fillers

\begin{tabular}{|c|c|c|c|c|c|c|}
\hline Parameters & $\begin{array}{c}\text { Unit of } \\
\text { measurement }\end{array}$ & $\begin{array}{c}\text { No. } 1 \\
\text { DEG with } \\
\text { GalenIQ } 721\end{array}$ & $\begin{array}{c}\text { No. } 2 \\
\text { DEG with } \\
\text { Prosolv HD } 90\end{array}$ & $\begin{array}{c}\text { No. } 3 \\
\text { DEG with } \\
\text { Prosolv SMCC } 50\end{array}$ & $\begin{array}{c}\text { No. } 4 \\
\text { DEG with } \\
\text { Vivapur } 102\end{array}$ & $\begin{array}{c}\text { No. } 5 \\
\text { DEG with } \\
\text { Vivapur } 112\end{array}$ \\
\hline $\begin{array}{l}\text { Bulk density } \\
\mathrm{m} / \mathrm{V}_{0}\end{array}$ & $\mathrm{~g} / \mathrm{ml}$ & $0.54 \pm 0.03$ & $0.55 \pm 0.04$ & $0.47 \pm 0.04$ & $0.45 \pm 0.03$ & $0.49 \pm 0.05$ \\
\hline $\begin{array}{l}\text { Tapped density } \\
\mathrm{m} / \mathrm{V}_{1250}\end{array}$ & $\mathrm{~g} / \mathrm{ml}$ & $0.70 \pm 0.02$ & $0.71 \pm 0.02$ & $0.70 \pm 0.03$ & $0.67 \pm 0.02$ & $0.71 \pm 0.04$ \\
\hline Carr Index & $\%$ & 23.91 & 21.1 & 51.4 & 48.64 & 31.37 \\
\hline Hausner Index & - & 1.3 & 1.27 & 1.51 & 1.48 & 1.46 \\
\hline $\begin{array}{c}\text { Flowability } \\
\text { without vibration }\end{array}$ & & $10.03 \pm 2.15$ & $\infty$ & $\infty$ & $\infty$ & $\infty$ \\
\hline $\begin{array}{l}\text { Flowability with } \\
\text { vibration }\end{array}$ & $\mathrm{s} / 100 \mathrm{~g}$ & $6.04 \pm 1.56$ & $13.13 \pm 1.48$ & $38.33 \pm 1.94$ & $15.80 \pm 2.05$ & $16.22 \pm 1.62$ \\
\hline Angle of repose & o & $33 \pm 1$ & $34 \pm 1$ & $36 \pm 1$ & $34 \pm 1$ & $35 \pm 1$ \\
\hline Disintegration & $\min$ & $10.450 .52 \pm$ & $>15$ & $>15$ & $>15$ & $>15$ \\
\hline
\end{tabular}

\section{Discussion of the research results}

Pharmaceutical development involves determination of the crystallographic characteristics of active pharmaceutical ingredients, excipients and their blends. As literature data analysis revealed, the physicochemical properties of excipients play a significant role in the selection of the composition of the finished medicinal product [22, 23].

To select the rational filler our attention was paid to the shape and size of the particles, their ability to agglomerate. The analysis of the mixture with Flowlac 100 (Fig. 1) has shown a non-uniform distribution of the extract in the filler. Flowlac 100 is rounded particles with a linear size of $0.5-0.6 \mu \mathrm{m}$. The form factor of the filler is 0.97 .

In the microscopic examination of the mixture with Tablettose 80 (Fig. 2) it has been found that the extract particles are different in shape and size. The form factor of Tablettose is $80-0.78$. The size of the filler particles is $0.45 \mu \mathrm{m}$.

Microcelac 100 (Fig. 3) particles have a rounded shape with a rough surface. The form factor of the filler is 1 . The linear size of particles is $1-1.5 \mu \mathrm{m}$.

The data presented in Fig. 4 also indicate a mismatch in the geometric dimensions of the extract particles and the Farmaxx filler. The filler has a rough surface and a spherical shape. The form factor of the filler is 0.93 . The particle size ranges from 1 to $1.35 \mu \mathrm{m}$. 
Therefore, the analysis of the mixtures with Flowlac 100, Tablettose 80, Microcelac 100, Farmaxx (Fig. 1-4) has shown that the particles of the extract and fillers differ in shape and the linear size, and it allows to predict the separation of the tablet mass when filling the matrix channel.

As can be seen from Fig. 5, there is a uniform distribution of the extract in the GalenIQ 721 filler. It should be noted, that the mass with this filler consists of particles, which are homogeneous by their linear size. The particle size of the extract ranges from 0.8 to $1.0 \mu \mathrm{m}$, while the size of the filler particles is $0.9-1.5 \mu \mathrm{m}$. Due to its inhomogeneous surface GalenIQ 721 binds the particles together, filling the voids of the extract surface.

As can be seen from Fig. 6, in the mixture with DEG the particles of Vivapur 112 (A) and Vivapur 102 (B) are of irregular shape with the linear sizes from $0.1 \mu \mathrm{m}$ to $1.1 \mu \mathrm{m}$. The form factor of the filler is 0.27 .

The results of studying the mixtures with Prosolv HD 90 and Prosolv SMCC 50 (Fig. 7) indicate that the particles of these fillers are of anisodiametric shape, which linear sizes vary from $0.1 \mu \mathrm{m}$ to $1 \mu \mathrm{m}$; the form factor of the filler is 0.36 .

Thus, when using different brands of Vivapur 112 and Vivapur 102 and mixtures of Prosolv HD 90 and Prosolv SMCC there is filling of the interparticle space of the extract and adhesion of small particles of excipients on its surface. It can lead to formation of a strong structure of the tablet mass.

The results of resistance of tablets to crushing showed that the samples with Prosolv HD 90 and Prosolv SMCC 50 having the maximum stability (more than $100 \mathrm{~N}$ ), the samples with GalenIQ 721 - more than 60 N, and model tablets with Vivapur 102 and Vivapur 112 - more than $40 \mathrm{~N}$ which met the SPHU requirements. The samples with Tablettose 80, Flowlac 100, Microcelac 100 , Farmaxx showed the minimal resistance (less than $40 \mathrm{~N}$ ), which did not meet the requirements of the SPhU.

The selected fillers from microscopic analysis and the resistance of tablets to crushing were subjected for further studies. As can be seen from the results presented (Fig. 9), the moisture absorption of the mixtures with different fillers is significantly different from the moisture absorption of the pure extract. The mixture with GalenIQ 721 has the least increase in moisture $(2.27 \%)$. With the rest of the fillers, the moisture absorption was almost the same, which was about $4 \%$.

At relative humidity up to $75 \%$ (Fig. 10) there is an increase in moisture from 5.21 to $5.66 \%$ in the samples with Prosolv HD 90, Prosolv SMCC 50, Vivapur 102 and Vivapur 112, in DEG - to $8 \%$, and in the mixture with GalenIQ 721 - to $4.32 \%$.

The tendency to increase the values of the moisture absorption is preserved at a relative humidity up to $100 \%$ (Fig. 11).

Thus, the results of the experiment have shown that the moisture absorption when adding excipients is significantly reduced compared to the original substance. The mixture with GalenIQ 721 has the lowest values of moisture increase.

As evidenced by the data given in Table 1, the mixture with Prosolv SMCC 50 (sample No. 3) and Vivapur 102 (sample No. 4) has a significant difference between the values of bulk density and tapped density and Carr Index over 38, which indicates their very poor flowability. Samples No. 3-5 are compacted much more than the mixture with GalenIQ 721 (sample No. 1) and Prosolv HD 90 (sample No. 2), and it suggests the use of greater pressure during compression. The angle of repose in all samples has approximately the same values; it indicates a significant force of adhesion between the particles of the mixtures. However, in contrast to samples No. 2-5, the mixture of GalenIQ 721 (sample No. 1) is able to flow under different conditions of the vibration funnel. The flow indicators are $9.97 \mathrm{~g} / \mathrm{s}$ and $16.55 \mathrm{~g} / \mathrm{s}$ without vibration and with vibration, respectively. By the disintegration time, only sample No. 1 met the requirements of the SPHU II ed., and did not exceed 15 min.

Thus, according to the results of the studies conducted, sample No. 1 was selected for further research.

\section{Conclusions}

1. Based on the crystallographic analysis, the ability to moisture absorption, resistance to crushing, disintegration time, flowability, angle of repose and bulk volume the effect of modern 
excipients on physicochemical and pharmaco-technological properties of the dry extract of ginger has been studied.

2. According to the results of microscopic analysis, it has been found that the rational fillers are GalenIQ 721, Prosolv HD 90, Prosolv SMCC 50, Vivapur 102 and Vivapur 112; they provide a uniform system and the necessary resistance to destruction.

3. The study of the kinetics of the moisture absorption has shown that addition of fillers significantly reduces the increase in moisture compared to the dry extract. The mixture with GalenIQ 721 has the lowest parameters of moisture absorption at a relative air humidity of $45 \%$, $75 \%$ and $100 \%$.

4. According to the results of the pharmaco-technological studies, it has been found that addition of GalenIQ 721 leads to improve flowability, disintegration, settling qualities; it indicates the feasibility of its inclusion into the composition of the solid dosage form.

5. The results obtained will be taken into account in further studies in development of the composition of tablets with the dry extract of ginger.

\section{References}

[1] Zheng, Y., Ley, S. H., Hu, F. B. (2017). Global aetiology and epidemiology of type 2 diabetes mellitus and its complications. Nature Reviews Endocrinology, 14 (2), 88-98. doi: http://doi.org/10.1038/nrendo. 2017.151

[2] Lotfy, M., Adeghate, J., Kalasz, H., Singh, J., Adeghate, E. (2016). Chronic Complications of Diabetes Mellitus: A Mini Review. Current Diabetes Reviews, 13 (1), 3-10. doi: http://doi.org/10.2174/15733 99812666151016101622

[3] Okur, M. E., Karantas, I. D., Siafaka, P. I. (2017). Diabetes Mellitus: A Review on Pathophysiology, Current Status of Oral Pathophysiology, Current Status of Oral Medications and Future Perspectives. ACTA Pharmaceutica Sciencia, 55 (1), 61-82. doi: http://doi.org/10.23893/1307-2080.aps.0555

[4] Fareed, M., Salam, N., Khoja, A. T., Mahmoud, M. A., Ahamed, M. (2017). Life Style Related Risk Factors of Type 2 Diabetes Mellitus and Its Increased Prevalence in Saudi Arabia: A Brief Review. International Journal of Medical Research \& Health Sciences, 6, 125-132.

[5] Governa, P., Baini, G., Borgonetti, V., Cettolin, G., Giachetti, D., Magnano, A. et. al. (2018). Phytotherapy in the Management of Diabetes: A Review. Molecules, 23 (1), 105-127. doi: http://doi.org/10.3390/ molecules23010105

[6] Bansode, T. S., Salalkar, B. K. (2017). Phytotherapy: Herbal medicine in the management of Diabetes mellitus. Plant Science Today, 4 (4), 161-165. doi: http://doi.org/10.14719/pst.2017.4.4.347

[7] Ilkhanizadeh, B., Shirpoor, A., Khadem Ansari, M. hasan, Nemati, S., Rasmi, Y. (2016). Protective Effects of Ginger (Zingiber officinale) Extract against Diabetes-Induced Heart Abnormality in Rats. Diabetes \& Metabolism Journal, 40 (1), 46-53. doi: http://doi.org/10.4093/dmj.2016.40.1.46

[8] Karimi, A., Majlesi, M., Rafieian-Kopaei, M. (2015). Herbal versus synthetic drugs; beliefs and facts. Journal of Nephropharmacology, 4, 27-30.

[9] Akinyemi, O., Oyewole, S. O., Jimoh, K. A. (2018). Medicinal plants and sustainable human health: a review. Horticulture International Journal, 2 (4), 194-195. doi: http://doi.org/10.15406/hij.2018. 02.00051

[10] Dhanik, J., Nand, N. A. V. (2017). A Review on Zingiber officinale. Journal of Pharmacognosy and Phytochemistry, 5, 174-184.

[11] Onianwah, I., Stanley, H. O. (2018). Comparative Study of the Antibacterial Activity of the Underground Stem of Ginger (Zingiber officinale) and the Bulb of Garlic (Allium sativum) on Selected Aerobic Bacterial Species. Electronic Journal of Biology, 14, 18-21.

[12] Kononenko, N. M., Chikitkina, V. V., Sorokina, M. V., Alkhalaf, M. W. (2018). Experimental rationale of selection of the hypoglicemic dose of ginger dry extract on normoglycemic rats. Farmatsevtychnyi Zhurnal, 1-2, 68-77. doi: http://doi.org/10.32352/0367-3057.1-2.18.08

[13] Hassan, N. A., Karunakaran, R., Sankar, A. U., Aye, K. M. (2016). Anti-Diabetic Effect of Zingiber Officinale on Sprague Dawley Rats. International Journal of Pharmacognosy and Phytochemical Research, 8, 1940-1943. 
[14] Alkhalaf, M. V., Ruban, O. A., Gerbina, N. A., Masliy, Yu. S. (2018). Studies of Physicochemical and Pharmacotechnological Properties of Zingiber Officinale Dry Extract. Journal of Pharmaceutical Science and Research, 10 (1), 5-7.

[15] Pedro, I. D. R., Brandão, I. C. C., Palhares de Souza, G. M. C., Carneiro, G. (2017). Development of tablet formulations of calcium carbonate by direct compression. Journal of applied pharmaceutical science, 4, 12-20.

[16] Olorunsola, E. O., Akpan, G. A., Adikwu, M. U. (2017). Evaluation of Chitosan-Microcrystalline Cellulose Blends as Direct Compression Excipients. Journal of Drug Delivery, 2017, 1-8. doi: http://doi. org/10.1155/2017/8563858

[17] Rowe, R. C., Sheskey, P. J., Cook, W. G., Fenton, M. E. (2012). Handbook of Pharmaceutical Excipients. Pharmaceutical Press and American Pharmacists Association, 1033.

[18] Teh, T. L. C., Abdul Majid, F. A., Iqbal, M. C. (2017). Development of DiabecineTM Tablet and Confirmation of Its Physical Properties and Pharmaceutical Safety Analysis. Sains Malaysia, 46 (4), 597-604. doi: http://doi.org/10.17576/jsm-2017-4604-12

[19] Zhydkova, T. N., Krutskykh, T. V. (2015). Some aspects of developing the production technology for combined tablets based on B vitamins. News Of Pharmacy, 4 (84), 26-30. doi: http://doi.org/10.24959/ nphj.15.2055

[20] Derzhavna Farmakopeia Ukrainy. Vol. 1 (2015). Kharkiv: Derzhavne pidpryiemstvo «Ukrainskyi naukovyi farmakopeinyi tsentr yakosti likarskykh zasobiv», 1128.

[21] Filimonova, A. V., Tretyakova, Y. A., Gavrilov, A. S., Soloduhina, L. A., Riabinin, A. E. (2016). Validol sugafree tablets: development of technology and production. Belgorod State University Scientific bulletin. Meditsina. Farmatsiya, 31 (16), 194-200.

[22] Zaychenko, V., Ruban, O., Maslii, Y., Gerbina, N. (2018). Physico-chemical and pharmaco-technological research at a substantiation of rational composition and technology of suppositories «indoxam». ScienceRise: Pharmaceutical Science, 5 (15), 17-23. doi: http://doi.org/10.15587/2519-4852.2018.146500

[23] Kovalevska, I. V., Borko, Ye. A., Poluian, S. M. (2019). A study of the influence of solvents on crystallographic characteristics of local anesthetics. Annals of Mechnikov Institute, 1, 17-22. 